\title{
Locked out, locked in and stuck: exploring migrant academics' experiences of moving to the UK
}

Toma Pustelnikovaite

This is a post-peer-review, pre-copyedit version of an article published in Higher Education. The final authenticated version is available online at: http://dx.doi.org/10.1007/s10734-020-00640-0 


\title{
Locked out, locked in and stuck: Exploring migrant academics' experiences of moving to the United Kingdom
}

\author{
Dr Toma Pustelnikovaite, Abertay University
}

\begin{abstract}
Current understanding of international academic mobility tends to view migrant academics as careeroriented actors who can follow opportunities across borders with relative ease. This paper offers a more nuanced reading of international mobility in academia by analysing how the professional context influences migrant academics' decisions to come to and remain in the United Kingdom (UK). Drawing on data from 62 semi-structured interviews with foreign-born academics employed in the UK, the paper argues that the availability of (relatively) good quality employment shapes international academic mobility more than country preferences. However, academics may become 'stuck' in the country of residence even when employment conditions deteriorate, not only because they are gradually tracked into country's higher education system and culture, but also because they lose the credentials, work experience and networks that may be needed to make another international move. This paper therefore shows that 'stickiness' in international mobility involves not only being 'locked into' a country but also being 'locked out' of another, and in so doing contributes to knowledge about the ways in which migrant academics become stuck whilst working abroad.
\end{abstract}

Keywords: migrant academics, international mobility, academia, UK, stickiness

\section{Introduction}

Migrant academics (MAs), understood as foreign-born individuals employed by a university on a teaching and/or research contract, are a crucial part of higher education in the United Kingdom (UK). A third of country's academics are from abroad (Lenihan and Witherspoon 2018), although the exact number varies based on the definition of 'migrant' being adopted (Coey 2018). MAs represent mobile talent believed to be key to the country's knowledge-based economic growth (Ackers and Gill 2008; Guth and Gill 2008; Cañibano and Woolley 2015). Thus, there is now a significant body of scholarship that seeks to better understand academics' international mobility motivations and experiences (Cattaneo et al. 2019; Cañibano and Woolley 2015; Morano-Foadi 2005; Jöns 2009).

Much of the literature documenting international mobility in academia tends to present MAs as careerfocused actors that can move across borders with relative ease (Morano-Foadi 2005; Oliver 2012; Bauman 2012). This paper questions similar perspectives and offers a more nuanced understanding of why MAs decide to come to and remain in an "academic superpower" (Altbach 2007 p.3608) country. The paper builds on work that analyses how MAs exercise their choices within their individualised framework of constraints (Ackers 2008; Bauder 2015; Lee and Kuzhabekova 2018) and on research that exposes the tensions and barriers in international academic mobility ${ }^{1}$ (Fernando and Cohen 2016; Loacker and Sliwa

\footnotetext{
${ }^{1}$ Literature has used the term 'international academic mobility' inconsistently. Some, for example, have adopted this term to discuss the migration of both students and faculty (e.g. Bilecen and Van Mol 2017; Leung 2017). This paper, however, views
} 
2016; Sang et al. 2013; Richardson 2009; Morley et al. 2018). While existing scholarship tends to examine how academics go about job transitions across borders, this paper looks at the migration challenges imposed upon MAs by the professional context that presumably facilitates international mobility (Enders and Kaulisch 2006). The aim of this paper is to identify how the professional context influences the (im)mobility decisions of foreign-born academics working in the UK.

The paper draws on the concept of 'stickiness' as a way of understanding how individuals become anchored to particular contexts. It contributes to the literature on MAs and to this special issue by showing that 'stickiness' in international mobility involves not only 'getting locked into' a country but also 'getting locked out' of other locations. The empirical material consists of 62 semi-structured interviews with foreign-born academics working in the UK. Findings show that factors such as the reputation of the UK's higher education sector, professional connections or the acquisition of location-specific capital gradually anchor MAs to UK's academia. Contemporarily, academics may also start losing the academic credentials, work experience and networks needed for another international move. MAs may thus 'become stuck' in the UK and not seek new career opportunities in other countries even if they are faced with deteriorating work and employment conditions.

The paper starts by reviewing literature on international mobility in academia. It then describes the research methods adopted in this study, and finishes by analysing and discussing the findings.

\section{International mobility in academia}

International mobility is an important element of contemporary academic careers. The Changing Academic Profession survey, for instance, shows that $42 \%$ of the 25282 participating academics from 19 countries have studied or worked in another country at least once (Rostan and Höhle 2014). Literature commonly frames academic migration in the context of macro-level debates on brain drain, brain gain and brain circulation/exchange (Cattaneo et al. 2019; Cañibano and Woolley 2015; Jöns 2009). Concerned with the impact of internationally mobile academics on sending and receiving countries, these debates highlight the value associated with one's 'brain' and tend to imply that there is a direct relationship between international migration and individual excellence (Ackers and Gill 2008; Cattaneo et al. 2019). Working abroad, MAs are often seen to outperform the local scholars in terms of research quantity and impact (Abramo et al. 2019; Fernando and Cohen 2016). Supposedly, then, it is the academics who are most committed to their profession (Enders and Kaulisch 2006) and who belong to "the best and the brightest" elite (Jonkers and Tijssen 2008) that succeed in gaining employment abroad.

Significant attention in the existing literature on MAs has thus been given to understanding the factors that influence academics' international mobility decisions. This area of research often draws on the economistic concepts of push and pull factors and rational decision making, assuming that people weigh the costs and benefits of a decision in order to make their choice. Frequently mentioned migration motivations are career-related, such as accessing a better research infrastructure and professional development opportunities, or wanting to acquire more credibility and benefit from the influence of renowned senior colleagues (Mahroum 2000; Richardson 2009; Toma and Villares-Varela 2019). Certain

'international academic mobility' as international migration of doctoral candidates and academics, in line with the conceptualisation in Musselin (2004), Lee and Kuzhabekova (2018) and Ortiga et al. (2018) among others. 
countries and universities are seen as better able to meet these aspirations than others (Lee and Kuzhabekova 2018; Bauder et al. 2017). English-speaking countries such as the US, Canada, Australia, New Zealand or the UK are portrayed as being at "the centre of the world academic system" (Enders and Musselin 2008 p.143). Consequently, they become attractive migration destinations for opportunityseeking academics (Altbach 2007).

A further strand of literature analyses MAs' labour market outcomes. Findings here are rather contradictory. On the one hand, international mobility is seen as being beneficial for scholars' career development (Leung 2017). MAs are attracted to higher education systems that have comparatively transparent recruitment, performance and progression requirements (Ackers 2003). Countries adopting standardised metrics such as the UK's Research Excellence Framework (REF) fare well in this respect (Afonso 2016). The presence of the REF may have thus contributed to the large numbers of MAs in the country. In the UK, migrant scientists also tend to cluster in the "golden triangle" consisting of Oxford, Cambridge and some London universities such as Imperial College (Ackers 2005). These universities provide MAs with international reputation, research experience and networking opportunities that are beneficial for their career progression in the UK and in other countries (Richardson 2009).

On the other hand, pursuing an international career is linked to numerous inequalities. To begin with, once universities adhere to metrics such as the REF and league tables, they also subscribe to the idea that these 'soft law' tools are a major way to judge quality in higher education (Paradeise and Thoenig 2013). Adhering to the REF criteria therefore offers international career opportunities to a particular type of MAs, namely those who specialise in producing highly-ranked publications and attracting funding rather than, for instance, committed teachers (Harley et al. 2004). In the UK, early-career MAs are indeed more likely to be recruited for research than teaching posts (Kim 2009). Furthermore, international academic mobility is gendered. Female academics have greater difficulties accessing international networks and collaboration opportunities useful for career progression compared to male academics (Zippel 2017). Finally, ethnicity also influences MAs' careers abroad. For example, ethnic minority academics may feel obliged to adjust to local academic cultures in order to progress with their careers, whereas Anglo white academics may not be under the same pressure (Sang and Calvard 2019).

Existing research on MAs is instructive in illuminating academic mobility trajectories, triggers and challenges. Yet, while attention to international academic mobility is increasing, being perpetually mobile is often presented as the norm. Current scholarship tends to portray international mobility as an outcome of a one-off individual decision (Czaika and Toma 2017), whereas migration is a process that also involves repeatedly re-evaluating the decision to move (King 2002). However, understanding why MAs may decide to remain abroad (i.e. be immobile) is limited (Fontes 2007). How decisions to move and to remain abroad are shaped by academics' professional context(s) remains particularly unclear (Richardson 2009; Ackers 2008; Bauder 2015). Professional context is understood as formal and informal social relations and the communities within and across disciplines (Duberley et al. 2006). It demarcates the (typical) pattern of an academic career in that country, and poses unique challenges for MAs. Musselin's (2004) study, for example, found that national academic systems in Europe contain implicit recruitment and performance expectations which inhibit the international mobility of European academics. The literature, however, often sees immobility as an individual failure that constrains one's opportunities to be exposed to new contexts, produce one's most creative work and not get stuck in one place as a researcher (Bauder 2015). Overall, then, there is a need to investigate how professional context(s) influence academics' (im)mobility decisions. 


\section{Conceptual context}

The idea that professional, social and personal contexts are 'sticky' offers a useful way to address the identified shortcomings in the work on international mobility in academia. 'Stickiness' talks about the ways in which individuals become anchored to particular contexts such as countries and workplaces (Coey 2013). It has been used in studies on highly-skilled migrants in disciplines as diverse as migration studies, management and higher education, with each discipline expanding the concept in different ways. Management studies have developed 'stickiness' conceptually, proposing it as a metaphor that captures the simultaneously appealing and unsettling nature of international mobility and positioning 'stickiness' as a counterpoint to the idea of migration as 'fluid' (Costas 2013). Migration and higher education studies have placed relatively more emphasis on the individual level of analysis (Coey 2013; Ackers 2005). These studies used 'stickiness' to remark on the embedding of individuals in specific geographies over their life course, suggesting that social networks and romantic relationships (Ackers 2005), emotional attachment to a place (Williams et al. 2004), acquired property or financial capital (Da Vanzo 1981) and limited resources to move elsewhere are among the factors that tie people to locations. Such examples demonstrate the analytical potential of the 'stickiness' concept for researchers from a variety of disciplines.

Despite its potential to offer important insights on (im)mobility, 'stickiness' has often been referred to only in passing and would benefit from further development as an analytical tool. In this respect, two main directions can be identified. First, studies tend to mention 'stickiness' in relation to individual's anchoring to either migrant's country of destination or the country of origin. However, migration is 'doubly embedded' (King 2002), meaning that migrants' decisions to leave and to remain are linked to the social processes in both countries at the same time (Gill 2005). As a result, this paper specifically seeks to understand how MAs' (im)mobility decisions are influenced by the concurring 'stickiness' of professional contexts in their country of destination and their country of origin.

Second, works referring to 'stickiness' have rarely taken into account that 'stickiness' is differential. MAs are a heterogenous group, and a specific country or workplace may be 'stickier' for some than it is for others (Bilecen and Van Mol 2017). Parenthood, for example, often anchors individuals to a particular location (Ackers 2005), yet it tends to limit the mobility of women more than that of men (Schaer et al. 2017). Of particular interest to this paper is the relationship between 'stickiness' and local/foreign 'academic nationality', understood as the country where one has obtained their PhD and became qualified for the job (Probst and Goastellec 2013). This focus is important because the stage of the academic career when one moves abroad is an emerging form of inequality among MAs (Shinozaki 2017). For example, doctoral candidates in the periphery of the global academic system may have fewer international migration opportunities in the future due to their supposedly less prestigious academic pedigree (Gerhards et al. 2018). Similarly, some academic systems are nepotistic and academics who study or work abroad may lack local networks needed to gain employment (Morano-Foadi 2005). Incorporating the 'double embeddedness' of migration and 'academic nationality' as an emerging marker of inequality will thus allow this paper to extend the engagement with the concept of 'stickiness' in the literature.

\section{Research methods}

This paper is based on qualitative data from 62 semi-structured interviews with foreign-born academics from countries across Europe, North and South America, Asia, Australia and Africa. Interviews with MAs 
sought to explore their experiences of migration to the UK, and specifically to understand their motivations of coming to and remaining in the UK. The first fourteen interviews constituted a pilot study which aimed to develop relevant lines of enquiry (Yin 2014). Exploring academics' motivations for coming to the UK provided an understanding of the circumstances in their countries of origin, whereas motivations to remain gave insights into academics' circumstances in the UK. Addressing these two areas enabled an analysis of the academics' individual framework of constraints in both their country of origin and destination, in line with the notion of the 'double embeddedness of migration' (King 2002).

The 62 academics were recruited using snowball sampling strategy. Criteria for participant recruitment were broad and comprised: (1) being foreign-born, and (2) being employed by a British university at the time of the interview. Data triangulation was built into the data collection process (Miles and Huberman 1994): having broad recruitment criteria allowed the researcher to compare MAs' experiences across different sub-categories, such as academic disciplines or countries of previous degrees. The final sample included 29 female and 33 male participants working in 13 British universities. 27 academics had a British doctoral degree whereas 35 acquired their doctoral degrees outside UK and moved to Britain for academic employment. For convenience, the former will be referred to as 'study migrants' while the latter will be regarded as 'work migrants'. In terms of academic disciplines (according to categories used by the UK's Higher Education Statistics Agency), 15 academics were from hard science disciplines, 31 from social sciences (of which 19 from social studies and 12 from business and management), and 16 from humanities. Finally, 3 participants were teaching fellows, 1 - senior teaching fellow, 5 - research fellows, 1 - scientific officer, 1 - senior research fellow, 31 - lecturers, 13 - senior lecturers, 4 - readers, and 3 were professors.

All of the interviews totalled 66 hours and 39 minutes. 51 interviews were conducted face-to-face, whereas the remaining 11 were conducted via telephone and Skype. Participants were provided with an information sheet which contained details about the aims and objectives of the study, and signed a consent form. Interviews were digitally recorded and transcribed by the author. Interviewees were also given the opportunity to review their interview transcripts to ensure that they were satisfied with the content and the degree of anonymity. Participants' names used in this paper are pseudonyms, and this study received ethical approval.

Collected data was analysed manually by developing a thematic coding framework (Boyatzis 1998). This framework was informed by a combination of inductive and deductive coding. Two higher-order themes were identified from the literature review and comprised the decision to come to the UK and the decision to remain in the UK. Inductive analysis of data relating to these two themes focused on the factors that influenced academics' (im)mobility decisions, paying particular attention to the professional context in academics' country of origin and country of destination. Inductive code development comprised marking key points and themes in transcripts and comparing them across interviews, particularly across study and work migrants (Emmel 2013).

The final stage of data analysis involved recognising pattern codes (Saldana 2009) which identified an emerging major theme or explanation in the data. Synthesis of inductively-developed codes and the conceptual framework of this research identified two processes that shaped academics' international mobility trajectories, namely 'getting locked out' of other countries, and 'getting locked into' the UK. Both of these processes illuminate ways in which professional context anchors MAs to the UK. The outcome of becoming anchored to the UK was that some MAs felt 'stuck'. Thus, 'getting locked out', 'getting locked 
into' and '(not) being stuck' are the three identified pattern codes which will be used as analytical categories to structure the exposition of findings.

\section{Findings}

\section{Getting locked out}

Echoing existing literature (Mahroum 2000; Sabharwal and Varma 2016), the narrative of serendipitously following good career opportunities across borders strongly featured in the (im)mobility decisions of academics interviewed in this study. Academics' decisions were influenced by cross-country differences in academic salary levels, division of labour, or access to permanent employment and work resources (Musselin 2004; Bauder 2015). However, MAs' focus on their career is to be treated with caution. Although coming to and remaining in the UK offered the possibility of relatively good study and work conditions compared to other countries, the UK was not necessarily the scholars' preference but often resembled a "last resort" (Kim 2015 p.611). Thus, 'getting locked out' of other countries was the first process that characterised interviewed academics' international mobility. This process shows that MAs had (or believed they had) limited opportunities to pursue an academic career in countries where they would have preferred to live and work. While earlier research pointed out that academics may become 'locked out' of their country of origin when they already work abroad (Gill, 2005), this study has found that professional contexts start locking MAs out before they make the decision to move.

The reasons for 'getting locked out' were multiple. To begin with, an academic career in scholars' countries of origin was often not feasible financially, for example because academic jobs were poorly remunerated or because academics could only obtain fixed-term academic employment contracts. This pattern was more common among work migrants, who already had first-hand experience of working conditions in another country. Andrej's (senior research fellow, Ukraine) story is typical of academics in this category. Andrej noted that remaining in Ukraine after the completion of his doctoral degree would have meant that he would not have been able to work in academia. Although Andrej "did not intend to leave Ukraine", his academic job there was so poorly paid that he had to seek additional employment in industry to pay the bills and support his family.

A different story of 'getting locked out' emerged from the accounts of academics from Continental Europe countries such as Germany, Italy, France and Spain. Academia in these countries is characterised by insularity, lack of career flexibility, and strong hierarchies (Musselin 2004, 2009). Consequently, academics whose careers did not fit the standard path of that country, for instance because they had moved into industry or because there were no jobs available in the university where they completed their doctoral degree, found themselves unable to access an academic career there. This rationale was mentioned by work and study migrants alike. For example, Artemis (lecturer, Greece) wanted to change careers and sought advice from her former university professors in Greece on where to pursue a Master's degree with a view of becoming an academic. Although Artemis wanted to stay in Greece, she was advised to "go to Britain." Similarly, Silke (lecturer, Germany) had a successful managerial career in the arts following the completion of her PhD in Germany. When she decided to return to academia, Silke only applied for UK academic jobs. Despite not wanting to leave her country of origin, Silke believed that she could not access an academic job in Germany because "you can't usually get in unless you really set out to stay in academia." 
Finally, a group of social sciences and humanities interviewees from Switzerland, Poland, Portugal, Greece and USA believed to be 'locked out' because they pursued critical approaches within their disciplines, and these were not welcome in their countries. This subset comprised both study and work migrants, but all moved to the UK later in their lives, after a career in industry or in academia of their countries of origin. Thanassis (lecturer, Greece), for instance, commented that in Greece his academic discipline

"is not very developed, it's still very much positivist, or conventionally constructivist in some circles. Bogged down in obsolete or archive debates, more or less debates that have been overcome in many ways."

Academics in this group were not willing to leave their countries of origin but found their opportunities to pursue a 'critical' academic career there to be limited. They therefore moved to the UK because (some) British universities offered them ontological empathy (Prasad 2013; Oliver 2010), i.e. the UK became the place where their scholarship was valued "holistically and not based on a restrictively defined notion of research output" (Prasad 2013 p.944).

Life and work in the UK, however, also gradually locked MAs out from an academic career elsewhere (Gill 2005). Working in the UK for a longer period of time, and in particular pursuing a doctoral education in UK and acquiring a British 'academic nationality', meant that scholars had not completed their PhDs with the 'right' people, or were losing the necessary senior connections, academic credentials, skills and work experience that could help them secure employment in the universities of their countries of origin or other higher education systems. Miklos (senior lecturer, Greece), for example, tried to enter several higher education systems as an 'outsider'. Having a Dutch PhD, he applied for academic jobs in multiple countries but "was getting the impression" that jobs in Italy, Spain, Greece or Germany "were offered to internal candidates and I stood a very low chance." The belief that their chances of working as an academic in their country of origin or elsewhere were limited stopped many from applying. Raquel (senior lecturer, Spain), for example, completed her doctoral degree in one of UK's most prestigious universities but was explicitly told by an eminent scholar in her country that “you will not get a job in Spain because you haven't been my student." Aurelie (lecturer, France) also did not see returning to France as a viable option. She has completed her doctoral degree in Britain, yet to get a job as an academic in France

"you have to have followed the right path. And doing your PhD in Britain is not part of the right path. The right path is to (...) do a PhD with the right supervisor. You know, the good supervisor with good connections."

Examples in this section demonstrate that MAs found it more important to pursue an academic career than to live in the country that they might have preferred. While this choice exemplifies interviewed academics' commitment to their profession and career (Kaulisch and Enders 2005; Ackers and Gill 2008), examples also highlight that international mobility may be somewhat involuntary, particularly among work migrants (Ortlieb and Weiss 2018). On the one hand, employment opportunities may exist in multiple countries but migrant scholars are not necessarily able to access them. On the other hand, participants' beliefs around following 'good career opportunities' masks the inability of various countries and universities to offer stable, well-remunerated and ontologically and epistemologically open academic jobs. MAs may therefore get 'stuck with' international mobility because it provides the most feasible option to practice their profession in a way that aligns with their priorities. 


\section{Getting locked into}

The second process that characterised MAs' international mobility consisted of 'getting locked into' the UK. This process shows that the UK's higher education system and culture gradually incorporate MAs in such a way that they cannot easily escape from it.

A number of MAs in this study started to 'get locked into' the UK prior to making the decision to move. First, some developed a personal or research interest in UK culture, or were already familiar with the country's university system, for instance by having studied in the UK through an Erasmus student exchange or by having established research networks there. Ilaria (assistant professor, Italy), for example, noted that seeing a job advert from a British university that she was already familiar with through her postgraduate studies and research networks "made quite a difference": she would not have applied for a job abroad and left Italy otherwise. Sabrina (lecturer, Germany) experienced a culture shock during her student exchange year in UK and left early; she felt that she had "failed", and wanted to return to the UK in order to prove herself. Second, the international reputation of UK higher education also contributed to locking MAs in. Some academics were chasing universities' prestige and were exclusively interested in Russell Group universities (Ackers 2005). Although few were attracted to come to the UK specifically, British universities' ability to offer research funding 'locked academics into' the country. Finally, the dominance of English as the main language of academic communication (Altbach 2015) was also a factor in MAs' choice of the UK over other countries. A number of interviewed academics only spoke English in addition to their native language. This "handicap of language" (Aamir, research fellow, Morocco) limited the number of countries where these academics could become full participants of local academic and public discourse, and the UK tended to be closer to MAs' family or to their area of research compared to other English-speaking countries.

Once in the UK, 'getting locked into' the country unfolded as "a process in stages" (Alessandro, senior lecturer, Italy) that encompassed interviewees' personal and professional lives. On a professional level, the first stage of locking MAs into the country was their decision to pursue a doctoral degree in the UK, which socialised them into the British academic profession (Reale et al. 2019). Carmen (assistant professor, Spain), for example, "would have loved to go back to Spain" after completing her British Master's degree but remained in the UK because she received a PhD scholarship. Although Carmen “didn't want to close the option of going back to Spain", she also "knew that by accepting this [PhD] option I was moving a little bit further." In other words, becoming part of British academic networks may have meant that Carmen lacked the necessary contacts and tacit/social knowledge of Spanish institutions. Similarly, once Alessandro (senior lecturer, Italy) made a decision to pursue a British PhD, staying in UK for his academic career became "pretty much obvious." The REF, however, was also mentioned as a factor that may 'lock MAs into' the country after the completion of their doctoral studies. Annike (senior lecturer, Germany), for example, believed that her international reputation within the discipline - and her ability to move internationally - would benefit more from one substantial monograph than from several journal papers which her department requires for the REF. Her experience is a reminder that, even as standardised metrics such as the REF may seek to facilitate academic mobility (Afonso 2016), they nonetheless remain nation-specific and promote a set of values that is prioritised in a particular country rather than being universal.

On a personal level, MAs gradually acquired "location-specific capital", i.e. "assets that are more valuable in their current location than they would be elsewhere" (Da Vanzo 1981 p.45). Interviewed academics 
were making local pension contributions, bought a house, had local friends, and their children attended local schools. Bryan (lecturer, USA), for example, has spent most of his working life in UK. He believed that returning to the USA was no longer an option because his British pension would leave him earning "about the same as a taxi driver" in the United States. Location-specific capital made MAs' potential departure from the UK more costly not only financially but also emotionally (Gill 2005). Consequently, for some, even smaller acquisitions such as buying furniture turned into difficult choices because these decisions restricted their perceived freedom of movement. As one participant pointed out,

“We just don't know. Should we buy a car? This is kind of settling in a bit much, committing a bit more." (Ryan, lecturer, Canada)

On the whole, 'getting locked in' shows that MAs became anchored to the country as they gained a better understanding of British culture, became part of local networks and institutions, and acquired British academic credentials, grants and work experience (Avveduto 2001). Study migrants have lived in the country longer than work migrants, and thus tended to be 'locked into' the UK more strongly. However, the importance of location-specific capital in academics' (im)mobility decisions highlights that MAs are perhaps less the instrumental opportunity seekers depicted in much of academic literature, but rather the social beings who make choices based on their own set of circumstances (Ackers 2008; Bauder 2015).

\section{(Not) being stuck}

The above discussion of MAs getting fixed in a particular geographical location shows that 'stickiness' in international mobility involves being 'locked into' a country while being 'locked out' of another. While some MAs experienced one process more strongly than the other, both featured in almost all accounts. In a sense, then, MAs were 'stuck' in the UK. Literature has generally depicted 'being stuck' as an undesirable state where one's life is on hold (Lahad 2012; Hage 2005; Straughan et al. 2020). Arguably, "one migrates because one feels stuck, not in order to feel stuck" (Hage 2005 p.470). Not all interviewed academics, however, experienced 'stuckness' negatively. Rather, their evaluation depended on their future migration aspirations within existing realities.

To illustrate how similar present circumstances can lead to different evaluations of one's 'stuckness', it is worth comparing Thanassis's (lecturer, Greece) and Ryan's (lecturer, Canada) accounts. The two lecturers arrived to the UK at a different stage of their careers, but both were inclined to return to their respective countries of origin. Ryan, a work migrant, approached his aspiration to return to Canada as a "very definite goal" that determined how he planned his career:

"I start structuring everything in my life to meet that goal. So I don't have to make myself appealing to the United Kingdom, I have to make myself appealing to my destination."

Emphasising the earlier observations that academic qualifications, work experience and interpersonal skills are nation-specific, Ryan's approach also exemplifies that moving to another country is not a oneoff decision (Czaika and Toma 2017) and may require a plan. Studies suggest that MAs retain the chance of returning to the country of origin for up to three years of living and working abroad because afterwards the crucial contacts and tacit/social knowledge tend to be lost (Gill 2005). Ryan had worked in a British university for two years, and did not feel 'trapped' in the UK because he proactively maintained links with Canada. Having lived and worked in the UK for nine years, a study migrant Thanassis believed his chances 
of returning to Greece were limited "because nobody's hiring" and because his critical research would not be supported. Thus, Thanassis has described his life and work in UK academia as a "forced exile", suggesting that he felt 'trapped' in the country. These examples suggest that professional context may be stickier for study migrants than for work migrants, even if both groups are 'getting locked into' a country while 'getting locked out' of others.

It is, however, important not to overgeneralise Thanassis's experiences and take into account his personal circumstances. Thanassis's realisation that he was 'stuck abroad' occurred upon receiving a permanent job offer which, he believed, limited his flexibility. Thanassis shared this experience with several other interviewees such as Margaux (senior lecturer, France) and Emily (lecturer, USA), who both moved to the UK for temporary employment. A similar rationale for 'feeling trapped' was also common among interviewees who were in a romantic relationship with a British person: they had compromised where to live and work. For example, Catherine (senior lecturer, Australia) felt "settled and trapped" in the UK because her relationship was "premised on the fact that I stay in the UK". These findings are important because MAs are more commonly seen as 'stuck' in various forms of uncertainty, such as their unclear status within the profession (Sang and Calvard 2019; Śliwa and Johansson 2015), temporary residence (Richardson 2009), or precarious jobs (Kim 2009; Oliver 2012). By contrast, Thanassis's, Emily's and Catherine's experiences show how the sense of 'being trapped' emerges from relative stability. This observation is not meant to suggest that uncertainty is better suited for MAs' plans (Piore 1979), nor that these accounts represent the experiences of most MAs in the UK. Nonetheless, it does point out that the sense of 'being stuck' may emerge from awareness that international mobility has not led to a substantial change in one's life while new international mobility possibilities are limited (Hage 2005; Costas 2013).

Many interviewed academics, however, claimed to have over time lost interest in moving to another country, and expressed having become 'rooted' rather than 'stuck' in the system. This experience was particularly common among study migrants, such as Yordanka (senior teaching fellow, Bulgaria). Yordanka believed that British culture has become part of her identity. She did not see herself as "entirely Bulgarian anymore", and expressed that returning to Bulgarian academia would make her "feel that I work in a foreign environment." A small group of academics also shared that working in the UK has liberated them from religious or personal constraints experienced in their countries of origin, and has transformed them personally (Coey 2018). Dinesh (scientific officer, Sri Lanka), for example, noted that by living in the UK he has "moved away from the typical Sri Lankan person". New country, (work)places and experiences have over time changed Dinesh in such a way that he was not sure he would "want to live there [in Sri Lanka] anymore".

Overall, academics' international mobility experiences show that work and life in the UK is a trade-off between being able to pursue the career they want and being distant from (some) family, friends and/or preferred lifestyle. Although professional contexts anchor study migrants more strongly than work migrants, academics' evaluation of the 'stickiness' of their international mobility mostly depended on their future migration aspirations. The next section will discuss the contributions of the main findings.

\section{Concluding comments}

This paper has sought to understand how professional context influences the international mobility decisions of MAs working in the UK. Drawing on 'stickiness' as an analytical tool, the paper has extended 
the engagement with this concept in literature on international mobility and added to the understanding of the tensions and barriers encountered by MAs.

The findings of this study challenge the ease of international migration in academia, showing that the professional context both gradually 'locks MAs out' of other countries, and 'locks them into' the UK. MAs start to 'get locked into' British academia by studying, developing research networks or interests in the UK, seeking prestige, as well as speaking English but no other foreign language. Contemporarily, the unsatisfactory experiences of higher education systems in other countries, characterised by unstable and poorly remunerated academic jobs or nepotism among other elements, mean that international mobility may seem to be the only opportunity for academics to pursue their chosen career. Unless academics proactively maintain links with other countries while living and working in the UK, they may gradually lose the academic credentials, skills, networks and work experience needed for another international move. This occurs because MAs become part of the local networks and institutions, and arrange their careers and work practices in line with the nation-specific requirements, such as those established in the REF. That academics get 'locked out of' and 'locked into' national professional contexts also suggests that success in academia is not necessarily based on boundaryless criteria (Enders and Kaulisch 2006). Rather, this comparison between study and work migrants has shown that professional contexts reward those academics who can demonstrate familiarity with the local higher education system, and penalise those who do not. Consequently, the ideal of an open international academic labour market seems to be far from being a reality (Musselin 2004; Kim 2017).

The implications of these findings are significant. The increasing number of MAs in the UK may give the impression that the UK is an attractive and open 'knowledge hub' (Rostan and Höhle 2014; Jöns 2015). Yet, behind prestige and opportunities associated with UK higher education are the increased managerialism and marketisation of the sector (Deem et al. 2010; Musselin 2013). UK academia is characterised by casualisation, emphasis on performance management, as well as 'publish or perish' pressures among others (Shattock 2007; Megoran and Mason 2020), with academic staff being "at breaking point" (Weale 2019). While this paper has found that academics' reasons to come to and remain in the UK are in part career-related (Kaulisch and Enders 2005; Ackers and Gill 2008), it has also shown that (im)mobility decisions are outcomes of academics becoming increasingly embedded in a particular location. Consequently, a number of MAs may be 'stuck with' the UK rather than being attracted by the UK, whether MAs frame this experience as 'being stuck' or as 'being rooted'. The more closed the academic cultures are elsewhere, and the worse the working conditions, the higher the number of MAs in Britain, even as work and employment conditions deteriorate. Although managerialism is believed to incentivise international and inter-university mobility through standardisation (Harley et al 2004), national higher education systems remain 'sticky'.

These observations point to interesting new avenues for research on international mobility in academia. First, the analysis of academics' (im)mobility decisions ultimately highlights that the underlying issue that needs to be addressed is the (in)ability of national higher education systems to offer accessible, ontologically and epistemologically open, well-remunerated and stable jobs. Therefore, there is a need for research that would critically examine MAs' work and employment conditions and inclusion in the UK and other countries. Second, a fruitful avenue for research would be to examine the extent to which the findings reported here are bound within the particular characteristics of UK academia. Finally, future research could develop a richer understanding of MAs 'getting locked into' as well as 'locked out of' particular contexts by analysing the intersection between academic nationality and other inequality 
markers such as gender, class and ethnicity. Overall, however, this paper has offered a nuanced examination of the relationship between MAs' (im)mobility decisions and the professional context. Interpreting migration as a process and analysing study and work migrants' circumstances in both their countries of origin and countries of destination has offered a dynamic perspective on migration and provided a more comprehensive understanding of international mobility in academia.

Acknowledgements: The author would like to thank Dr Charikleia Tzanakou, Dr Emily Henderson, Dr Tricia Tooman and the anonymous reviewers for their valuable comments on the earlier drafts of this paper. The author is also thankful to Dr Shiona Chillas for her intellectual contribution to, and supervision of, the doctoral project from which this article is drawn.

Funding: This work was supported by the $600^{\text {th }}$ Anniversary PhD Scholarship provided by the School of Management, University of St Andrews. 


\section{References}

Abramo, G., D'Angelo, C.A. and Di Costa, F. (2019). A nation's foreign and domestic professors: which have better research performance? (the Italian case). Higher Education, 77(5), 917-930.

Ackers, L. (2008). Internationalisation, Mobility and Metrics: A New Form of Indirect Discrimination?. Minerva 46, 411-435.

Ackers, L. (2005). Moving People and Knowledge: Scientific Mobility in the European Union. International Migration, 43(5), 99-131.

Ackers, L. (2003). The participation of women researchers in the TMR Marie Curie Fellowships 1994-1998. Brussels: Court of Justice of the European Communities.

Ackers, L. and Gill, B. (2008). Moving People and Knowledge: Scientific Mobility in an Enlarging European Union. Cheltenham: Edward Elgar Publishing Ltd.

Afonso, A. (2016). Varieties of Academic Labor Markets in Europe. PS: Political Science and Politics, 49(4), 816-821.

Altbach, P. (2015). The Imperial Tongue: English as the Dominating Academic Language. International Higher Education, 42(49), 3608-3611.

Altbach, P.G. (2007). Globalization and the university: Realities in an unequal world. In: Forest, J. J. F. and Altbach, P. G. (eds.) International Handbook of Higher Education. Dodrecht: Springer, pp. 121-139.

Avveduto, S. (2001). International mobility of PhDs. In: OECD (ed.) Innovative People: Mobility of Skilled Personnel in National Innovation Systems. Paris: OECD Publishing, pp. 229-242.

Bauder, H. (2015). The International Mobility of Academics: A Labour Market Perspective. International Migration, 53(1), 83-96.

Bauder, H., Hannan, C.A., Lujan, O. (2017). International Experience in the Academic Field: Knowledge Production, Symbolic Capital, and Mobility Fetishism. Population, Space and Place, 23(6).

Bauman, Z. (2012). Globalization: The Human Consequences. Cambridge: Polity Press.

Bilecen, B. and Van Mol, C. (2017). Introduction: international academic mobility and inequalities. Journal of Ethnic and Migration Studies, 43(8), 1241-1255.

Boyatzis, R.E. (1998). Transforming Qualitative Information: Thematic Analysis and Code Development. Thousand Oaks, California: Sage Publications.

Cañibano, C. and Woolley, R. (2015). Towards a Socio-Economics of the Brain Drain and Distributed Human Capital. International Migration, 53(1), 115-130.

Cattaneo, M., Malighetti, P., Paleari, S. (2019). The Italian brain drain: cream and milk. Higher Education, $77(4), 603-622$.

Coey, C. (2013). International Academics in English Higher Education: Practicing and Capturing Mobile Careers. University of Liverpool. [PhD thesis]

Coey, C. (2018). International researcher mobility and knowledge transfer in the social sciences and humanities. Globalisation, Societies and Education, 16(2), 208-223. 
Costas, J. (2013). Problematizing Mobility: A Metaphor of Stickiness, Non-Places and the Kinetic Elite. Organization Studies, 34(10), 1467-1485.

Czaika, M. and Toma, S. (2017). International academic mobility across space and time: The case of Indian academics. Population, Space and Place, 23(8).

Deem, R., Hillyard, S., Reed, M. (2010). Knowledge, Higher Education, and the New Managerialism. Oxford: Oxford University Press.

Duberley, J., Cohen, L., Mallon, M. (2006). Constructing Scientific Careers: Change, Continuity and Context. Organization Studies, 27(8), 1131-1151.

Emmel, N. (2013). Sampling and choosing cases in qualitative research: a realist approach. London: Sage.

Enders, J. and Kaulisch, M. (2006). The binding and unbinding of academic careers. In: Teichler, U. (ed.) The Formative Years of Scholars. London: Portland Press, pp. 85-95.

Enders, J. and Musselin, C. (2008). Higher Education to 2030, Volume 1, Demography. Paris: OECD.

Fernando, W.D.A. and Cohen, L. (2016). Exploring career advantages of highly skilled migrants: a study of Indian academics in the UK. The International Journal of Human Resource Management, 27(12), 12771298.

Fontes, M. (2007). Scientific mobility policies: how Portuguese scientists envisage the return home. Science and Public Policy, 34(4), 284-298.

Gerhards, J., Hans, S., Drewski, D. (2018). Global inequality in the academic system: effects of national and university symbolic capital on international academic mobility. Higher Education, 76(4), 669-685.

Gill, B. (2005). Homeward bound? The experience of return mobility for Italian scientists. Innovation: The European Journal of Social Science Research, 18(3), 319-341.

Guth, J. and Gill, B. (2008). Motivations in East-West Doctoral Mobility: Revisiting the Question of Brain Drain. Journal of Ethnic and Migration Studies, 34, 825-841.

Hage, G. (2005). A not so multi-sited ethnography of a not so imagined community. Anthropological Theory, 5(4), 463-475.

Harley, S., Muller-Camen, M., Collin, A. (2004). From academic communities to managed organisations: The implications for academic careers in UK and German universities. Journal of Vocational Behavior, 64(2), 329-345.

Jonkers, K. and Tijssen, R. (2008). Chinese researchers returning home: Impacts of international mobility on research collaboration and scientific productivity. Scientometrics, 77(2), 309-333.

Jöns, H. (2009). 'Brain circulation' and transnational knowledge networks: studying long-term effects of academic mobility to Germany, 1954 - 2000. Global Networks, 9(3), 315-338.

Jöns, H. (2015). Talent Mobility and the Shifting Geographies of Latourian Knowledge Hubs. Population, Space and Place, 21(4), 372-389.

Kaulisch, M. and Enders, J. (2005). Careers in overlapping institutional contexts. Career Development International, 10(2), 130-144.

Kim, E.C. (2015). International professors in China: Prestige maintenance and making sense of teaching 
abroad. Current Sociology, 63(4), 604-620.

Kim, T. (2017). Academic mobility, transnational identity capital, and stratification under conditions of academic capitalism. Higher Education, 73(6), 981-997.

Kim, T. (2009). Transnational academic mobility, internationalization and interculturality in higher education. Intercultural Education, 20(5), 395-405.

King, R. (2002). Towards a new map of European migration. International Journal of Population Geography, 8, 89-106.

Lahad, K. (2012). Singlehood, Waiting, and the Sociology of Time. Sociological Forum, 27(1), 163-186.

Lee, J.T. and Kuzhabekova, A. (2018). Reverse flow in academic mobility from core to periphery: motivations of international faculty working in Kazakhstan. Higher Education, 76(2), 369-386.

Lenihan, A. and Witherspoon, S. (2018). A World of Talent: International Staff at UK Universities and the Future Migration System (First Report). London: Campaign for Social Science.

Leung, M.W.H. (2017). Social Mobility via academic mobility: reconfigurations in class and gender identities among Asian scholars in the global north. Journal of Ethnic and Migration Studies, 43(16), 27042719.

Loacker, B. and Sliwa, M. (2016). 'Moving to stay in the same place? Academics and theatrical artists as exemplars of the 'mobile middle. Organization, 23(5), 657-679.

Mahroum, S. (2000). Highly skilled globetrotters: mapping the international migration of human capital. R\&D Management, 30(1), 23-31.

Megoran, N. and Mason, O. (2020). Second class academic citizens: The dehumanising effects of casualisation in higher education. London: UCU.

Miles, M.B. and Huberman, A.M. (1994). Qualitative Data Analysis: An Expanded Sourcebook. Thousand Oaks, California: Sage Publications.

Morano-Foadi, S. (2005). Scientific Mobility, Career Progression, and Excellence in the European Research Area. International Migration, 43(5), 133-162.

Morley, L., Alexiadou, N., Garaz, S., González-Monteagudo, J., Taba, M. (2018). Internationalisation and migrant academics: the hidden narratives of mobility. Higher Education, 76(3), 537-554.

Musselin, C. (2013). Redefinition of the relationships between academics and their university. Higher Education, 65(1), 25-37.

Musselin, C. (2009). The Market for Academics. Oxon: Routledge.

Musselin, C. (2004). Towards a European Academic Labour Market? Some Lessons Drawn from Empirical Studies on Academic Mobility. Higher Education, 48(1), 55-78.

Oliver, E.A. (2012). Living flexibly? How Europe's science researchers manage mobility, fixed-term employment and life outside work. The International Journal of Human Resource Management, 23(18), 3856-3871.

Oliver, C. (2010). The Goals of Scholarship. Journal of Management Inquiry, 19(1), 26-32. 
Ortlieb, R. and Weiss, S. (2018). What makes academic careers less insecure? The role of individual-level antecedents. Higher Education, 76(4),571-587.

Ortiga, Y. et al. (2018). Academic 'Centres', Epistemic Differences and Brain Circulation. International Migration, 56(5),90-105.

Paradeise, C. and Thoenig, J.C. (2013). Academic Institutions in Search of Quality: Local Orders and Global Standards. Organization Studies, 34(2),189-218.

Piore, M.J. (1979). Birds of Passage: Migrant labor and industrial societies. Cambridge: Cambridge University Press.

Prasad, A. (2013). Playing the game and trying not to lose myself: a doctoral student's perspective on the institutional pressures for research output. Organization, 20(6), 936-948.

Reale, E., Morettini, L., Zinilli, A. (2019). Moving, remaining, and returning: international mobility of doctorate holders in the social sciences and humanities. Higher Education, 78(1),17-32.

Richardson, J. (2009). Geographic Flexibility in Academia: A Cautionary Note. British Journal of Management, 20(s1), S160-S170.

Rostan, M. and Höhle, E.A. (2014). The International Mobility of Faculty. In: Huang, F., Finkelstein, M., and Rostan, M. (eds.) The Internationalization of the Academy. Dordrecht: Springer Netherlands, pp. 79-104.

Sabharwal, M. and Varma, R. (2016). Return Migration to India: Decision-Making among Academic Engineers and Scientists. International Migration, 54(4),177-190.

Saldana, J. (2009). The Coding Manual for Qualitative Researchers. London: Sage.

Sang, K., Al-Dajani, H., Özbilgin, M. (2013). Frayed Careers of Migrant Female Professors in British Academia: An Intersectional Perspective. Gender, Work \& Organization, 20(2),158-171.

Sang, K.J.C. and Calvard, T. (2019). 'I'm a migrant, but I'm the right sort of migrant': Hegemonic masculinity, whiteness, and intersectional privilege and (dis)advantage in migratory academic careers. Gender, Work \& Organization, 26(10),1506-1525.

Schaer, M., Dahinden, J., Toader, A. (2017). Transnational mobility among early-career academics: gendered aspects of negotiations and arrangements within heterosexual couples. Journal of Ethnic and Migration Studies, 43(8), 1292-1307.

Shattock, M. (2007). United Kingdom. In Forest, J. J. F. and Altbach, P. G. (eds) International Handbook of Higher Education (pp. 1019-1033). Dordrecht: Springer.

Shinozaki, K. (2017). Gender and citizenship in academic career progression: an intersectional, meso-scale analysis in German higher education institutions. Journal of Ethnic and Migration Studies, 43(8), 13251346.

Śliwa, M. and Johansson, M. (2015). Playing in the academic field: Non-native English-speaking academics in UK business schools. Culture and Organization, 21(1), 78-95.

Straughan, E., Bissell, D., Gorman-Murray, A. (2020). The politics of stuckness: Waiting lives in mobile worlds. Environment and Planning C: Politics and Space. [online first].

Toma, S. and Villares-Varela, M. (2019). The Role of Migration Policies in the Attraction and Retention of International Talent: The Case of Indian Researchers. Sociology, 53(1), 52-68. 
Da Vanzo, J. (1981). Repeat Migration, Information Costs, and Location-Specific Capital. Population and Environment, 4(1), 45-73.

Weale, S. (2019). Higher education staff suffer 'epidemic' of poor mental health. The Guardian. Available at: https://www.theguardian.com/education/2019/may/23/higher-education-staff-suffer-epidemic-ofpoor-mental-health. [accessed: 24/05/2019]

Williams, A.M., Baláž, V., Wallace, C. (2004). International Labour Mobility and Uneven Regional Development in Europe. European Urban and Regional Studies, 11(1), 27-46.

Yin, R.K. (2014). Case study research: design and methods. London: Sage.

Zippel, K. (2017). Women in global science: Advancing academic careers through international collaborations. Stanford: Stanford University Press. 